\title{
DOVER, KILMER, MAZEL: HISTORIOGRAFIA ESSENCIALISTA
} DO HOMOEROTISMO GREGO

DANIEL BARBO ${ }^{1}$

Resumo: Este artigo faz uma análise do modo essencialista com que os historiadores Kenneth Dover, Martin Kilmer e Jacques Mazel abordaram o homoerotismo grego numa época posterior ao evento de Stonewall (1969).

Palavras-chave: Homoerotismo Grego; Historiografia; Dover; Kilmer; Mazel.

A partir da década de 1970, inicia-se uma longa e renovada historiografia do homoerotismo grego, colocando em debate uma relação entre o fenômeno grego (a paiderastía) e o fenômeno moderno (a homossexualidade). De cunho essencialista, esta historiografia analisou a erótica grega em termos de hetero- e homossexualidade (tais identidades seriam, para esta matriz historiográfica, essências humanas universais e não construções culturais datadas), obscurecendo a explicação do próprio fenômeno grego e, concomitantemente, dialogou com

\footnotetext{
1 Doutor em História e Cultura Políticas Pela Universidade Federal de Minas Gerais. E-mail: danielbarbo@yahoo.com.br.
}

os diversos movimentos de libertação e conquista de cidadania por parte dos grupos homossexuais. A própria possibilidade do surgimento dessa historiografia, falando abertamente dos amores e dos relacionamentos eróticos entre iguais no mundo grego é consequência da nova mentalidade adquirida a partir dos movimentos de libertação e contestação das décadas de 1960/1970. Da inter-relação entre essas duas ordens de fontes (historiografia essencialista do fenômeno grego e historiografia/sociologia/antropologia da homossexualidade), numa dialética entre escrita historiográfica e grupos, movimentos, simbologias, ativismo, militância, direitos de cidadania, crenças, rituais, festas, estilos de vida e identidade homossexuais, verifica-se e delineia-se outra etapa da cultura política homoerótica. Esboçaremos, então, as feições desta Cultura Política: uma cultura historicamente diversificada que quer conquistar um espaço na cidadania, um lugar de liberdade na modernidade/pós-modernidade. Um embate que está em marcha no que podemos chamar de Processo Civilizador ${ }^{2}$ da modernidade.

2 Cf. ELIAS, Norbert. 0 processo civilizador 1: Uma história dos costumes, 1994; 0 processo civilizador 2: Formação do estado e civilização, 1993. 
O clima autoritário e conservador no mundo ocidental nas décadas de 1940 e 1950 justificam, em parte, a superficialidade das análises e as concepções historiográficas surgidas naquela época. A situação permaneceu assim até a liberalização dos costumes, nos Estados Unidos e na Europa, nos anos 1960/70, período em que se inicia uma revisão radical dos conhecimentos e das concepções sobre o homoerotismo grego. Entre 1967 e 1969, em cidades como Nova lorque, Amsterdã e Berlim, ocorrem revoltas libertárias por parte dos homossexuais, transformadas em grande parte em uma revolução comportamental, contra o preconceito e a repressão. Assumia-se a condição homossexual como um desafio político perante a família e o Estado, identificados com a repressão social. O uso do corpo assumia as feições de uma arma contra a ordem. Este novo clima proporcionou o evento Stonewall e suas consequências mundiais.

Gay Liberation Front - GLF (Frente de Libertação Gay) era o nome de vários grupos de libertação gay. O primeiro destes grupos formou-se em Nova lorque em 1969 imediatamente após os protestos decorrentes de Stonewall. Um dos primeiros atos da GLF nova-iorquina foi organizar uma marcha em resposta às violências de Stonewall, exigindo o fim das perseguições aos homossexuais. O grupo tinha uma ampla plataforma política, denunciando o racismo e declarando apoio a várias lutas no Terceiro Mundo e ao Black Panther Party. Alguns destes apoiados retribuíram o gesto de solidariedade. 0 grupo tomou uma posição anticapitalista e atacou o modelo de família nuclear e os tradicionais papéis de gênero estabelecidos na sociedade capitalista. A GLF não se dedicava apenas aos direitos dos gays, mas também aos ideais sociais mais amplos que dominaram a década de 1960, incluindo paz, igualdade e justiça econômica. A missão primária da GLF era opor-se e lutar contra as instituições que, historicamente, tinham oprimido e rebaixado os gays. Idealmente, a GLF queria assegurar que os gays fossem tratados com crescente igualdade. Para isso, organizou e participou de marchas, demonstrações, discursos, confrontos, greves, teatro de rua, encontros, livros, filmes e movimentos destinados a desestabilizar eventos que promovessem precon- ceitos aos gays. Tudo isso, na tentativa de aumentar a consciência de sua causa e sua luta. O grupo também se engajou na técnica do "assumir-se" (por exemplo, fazendo incursões em bares gays, gritando e constrangendo os presentes a 'saírem do armário', tentando forçá-los a 'se assumir'), a qual muitos ativistas lamentaram anos depois. Entre 1969 e 1972, a GLF foi uma força muito influente, consistindo-se em mais de 80 grupos independentes espalhados pelos Estados Unidos e por outros países.

A GLF londrina nasceu em 1970, também inspirada nas lutas de Stonewall e seguindo os passos dos movimentos homossexuais dos Estados Unidos. Era radical a vontade de publicidade da condição homossexual entre os militantes londrinos. Definindo-se como uma organização revolucionária, a GLF londrina e, portanto, o poder gay, tinha como modelo o poder negro. O sentimento particular e inebriante de poder agir e falar abertamente sobre sua condição gay era o denominador comum que unia os diversos membros do grupo, entre os quais artistas, marginalizados e dependentes da Previdência, além de professores, estudantes e sociólogos. Os militantes londrinos consideravam que o primeiro passo para o engajamento político no movimento era a atitude de aceitar a condição homossexual; a reivindicação pelo fim da opressão e da discriminação estava condicionada a atitudes individuais e coletivas como beijar, abraçar e andar de mãos dadas pelas ruas. Mas antes de tornar pública a condição homossexual para familiares e amigos, era necessário que os gays se mostrassem para si mesmos, sentindo-se capazes de encarar sua própria natureza, e não mais enxergar a si mesmos através dos olhos da sociedade. O gesto revolucionário que a GLF britânica ensejava era o orgulho de si mesmo enquanto homossexual. Só com essa aceitação seria possível abrir-se para familiares e amigos e vencer a vergonha e a humilhação que, frequentemente, a sociedade impunha aos homossexuais (SPENCER, 1999, p. 349).

Essa fase de exposição e publicidade foi muito importante para dar força ao grupo londrino. Ao mesmo tempo, oferecendo "à sociedade uma nova perspectiva semiótica, bem diferente e muito mais 
agressiva", o grupo desafiava todos os velhos estereótipos homossexuais: "os valores do gueto, bares e pubs gays, os territórios de sexo conhecidos como 'mercado de carne', o circuito dos locais de encontros, a fada deslumbrada e a queen de punhos delicados". Pubs que recusavam a presença de gays foram denunciados publicamente. Espaços próprios, como discotecas, foram criados, "onde homens e mulheres homossexuais podiam se encontrar e passar uma noite agradável, numa atmosfera relaxante e sem a tensão e o clima pesado dos locais tradicionais de encontro." Em todas essas atividades, o Movimento de Libertação Feminina uniu forças com a GLF londrina. Criaram-se os dias gays e a semana do orgulho gay (já instituída nos Estados Unidos em 1970, cuja celebração encerrava-se com uma passeata pela Christopher Street, comemorando as lutas de Stonewall). O grupo londrino promoveu, ainda, em 1972, com a participação de dois mil homens e mulheres, uma marcha através de Londres até o Hyde Park (SPENCER, 1999, p. 350).

O manifesto da GLF londrina, escrito no início de 1971, apontava para uma nova percepção da condição homossexual, a "percepção a respeito do que a sociedade havia feito aos homossexuais". Os papéis que os gêneros desempenham no seio da família tradicional, o macho dominante, a mulher escrava e os filhos forçados a moldar seu comportamento pelo dos pais, representavam uma opressão com a qual se excluía a homossexualidade, sentida como inferior ou como perversão doentia. "Todos os homens gays tinham profunda consciência de que a sociedade os via como homens fracassados, que eram isolados e passíveis de ser tratados a qualquer momento pela psiquiatria como doentes ou desviantes - ou então punidos em julgamentos públicos ou condenados à prisão." Nestas condições, três caminhos restavam para os homossexuais: o anonimato, o comportamento afetado que convidava ao riso, ou a autorrejeição, quando concordavam tacitamente com a visão que a sociedade tinha deles, o que levava à vergonha e à culpa. Também, percebeu-se que as próprias relações homossexuais seguiam um padrão social heterossexual, ou seja, a estrutura marido/mulher era dominante nas relações sexuais (SPENCER, 1999, p. 350-351).
No campo historiográfico, e sob a égide desses movimentos contestatórios, Kenneth J. Dover, Felix Buffière, Jacques Mazel, Catherine Salles, Giuseppe Cambiano, Martin F. Kilmer fazem uma análise descritiva e essencialista do fenômeno homoerótico grego.

O modo como gostaríamos de analisar esta matriz historiográfica remete-nos para as relações complexas entre a História dos Conceitos e a História Social ${ }^{3}$. Importa-nos interrogar os usos que se fizeram das categorias sexuais modernas, especialmente a categoria homossexualidade, e consagrar-Ihe o estudo de sua imagem temporal. Igualmente, em conexão com este estudo, importa-nos investigar a imagem temporal da paiderastía nessa historiografia. Quais relações esses historiadores estabeleceram, em seu tempo, entre a categoria moderna homossexualidade e a categoria grega paiderastía na longa duração da produção dessa historiografia essencialista? Como essa produção historiográfica conjugou, associou ou dissociou, no que tange à esfera erótica e a cultura política que ela engendra, o Mundo Grego e a Modernidade?

Dover, em sua obra $A$ homossexualidade na Grécia Antiga, publicada em 1978, fez um amplo estudo lexical e iconográfico da prostituição masculina e da legislação na Atenas clássica, evidenciando a real amplitude das relações eróticas entre homens. Sartre afirmou que com essa obra

caía um tabu implícito, pois Kenneth Dover sublinhava ao mesmo tempo a freqüência do fenômeno pederástico e a dimensão sexual das relações amorosas, que iam além da amizade viril de companheiros de caserna ou do vínculo privilegiado de ordem pedagógica, mais espiritual que carnal (SARTRE, 1999, p. 5).

No intuito de compreender a importância dessa obra para o seu tempo, verificando a sua recepção entre os eruditos, citemos uma crítica positiva. John Scarborough, da University of Kentuky, escreveu em 1979:

3 Sobre História dos Conceitos e Tempos Históricos, ver KOSELLECK, 2006. 
Greek Homosexuality fornece - finalmente um olhar sem verniz da homossexualidade ateniense pelo que ela era. É um livro cuidadosamente construído e é agora o volume standard sobre o assunto. O domínio de Dover sobre as fontes é, como sempre, completo e seguro, mas o livro sofre de uma irritante hesitação: o autor nunca nos informa completamente o que ele pensa sobre todos os materiais em mãos. Catedráticos e professores de todos os níveis não devem ter dúvidas de que este é um livro para se recomendar aos estudantes e leitores em geral. Ele disponibiliza "os fatos" tais quais eles podem ser conhecidos. (SCARBOROUGH, 1979 , p. 1029) ${ }^{4}$

\section{A homossexualidade na Grécia Antiga é,} na visão de Halperin (1990, p. 4-5), uma obra pioneira e muito importante para os estudos do homoerotismo grego. Representa uma bem documentada pesquisa empírica sobre a iconografia, o léxico ${ }^{5}$ e as expressões daquele universo erótico. Halperin aponta os fatos básicos levantados nessa obra que, doravante, norteariam os estudos da erótica grega:

A abordagem insistentemente empírica de Dover alcançou sua proposta principal, que era estabelecer de uma vez por todas alguns fatos básicos sobre a 'homossexualidade grega' face ao ceticismo da parte de eruditos clássicos tradicionais. Os principais pontos de Dover eram (1) que o comportamento homossexual entre os homens gregos, em grande parte, tomou a forma de relações pederásticas entre um homem e um jovem; (2) que os gregos clássicos consideravam normal e natural o desejo de homens adultos por prazer sexual através do contato com belos jovens; (3) que nenhuma lei ou costume atenienses proibiam ou penalizavam a expressão sexual de tal desejo, contanto que os amantes observassem certas decências convencionais; e (4) os casos de amor pederásticos que seguiam, pelo menos aparentemente, as regras daquelas convenções eram

\footnotetext{
${ }^{4}$ Ver também ROBINSON, T. M. [untitled] Reviewed work: Greek Homosexuality by K. J. Dover. Phoenix, Vol. 35, № 2, 1981. Para uma crítica metodológica muito negativa, ver DEMAND, Nancy. [untitled] Reviewed work: Greek Homosexuality by K. J. Dover. The American Journal of Philology, v. 101, № 1, 1980.

${ }^{5}$ Foram analisados termos como Eros, Erastés, Erómenos, Philia, Paidica, Pais, Paiderastía, Pornos, Peporneumenos, Hetairekos, Hybris (Hybristes; Hybrizein), Sophrosyne (Sophron), Agapan, Agape, entre muitos outros.
}

considerados, pela sociedade ateniense, como decentes, honrados e - sob certas circunstâncias-mesmo louváveis (HALPERIN, 1990, p. 5).

Embora Dover não estivesse fundamentalmente preocupado com questões teóricas, "ele trabaIhou dentro de uma tradição de pesquisa empírica cujos objetivos e métodos estava preparado para justificar". John Boswell questionou o ponto (1) e David Cohen tentou refutar os pontos (2) e (3), mas Halperin considera que nenhum dos dois fora capaz de abalar os principais resultados da pesquisa de Dover e que é improvável que alguém mais o seja. (HALPERIN, 1990, p. 5)

Tendo como fontes básicas a iconografia de vasos pintados entre 570 e 470 a.C.; a poética atribuída a Teógnis de Mégara do final do período arcaico e início do período clássico; a comédia ática, especialmente Aristófanes e seus contemporâneos; a pessoa de Platão e a filosofia platônica; o discurso forense Contra Timarco do orador e político ateniense Ésquines do século IV a.C. e epigramas compostos a partir do século III a. C. e incorporados a diversas antologias, das quais a mais antiga e importante fora a Guirlanda de Meleagro, Dover, em sua obra pioneira, tem como objetivo "descrever os sentimentos e comportamentos homossexuais retratados na arte e na literatura gregas, entre o oitavo e o segundo século a.C." (DOVER, 1994, p. 7, Grifos nossos)

Analisando o Contra Timarco de Ésquines, Dover diz que este autor começará a sua acusação a partir do período no qual Timarco "era um jovem adolescente (meirakion) e passava seus dias na clínica de um médico, aparentemente para aprender a medicina, mas na realidade para aprender os costumes homossexuais" (DOVER, 1994, p. 40, Grifos nossos). O texto original do Contra Timarco a que Dover se refere, diz:

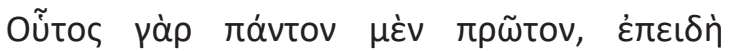

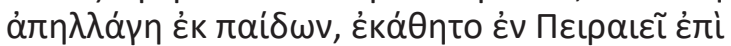

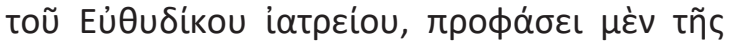

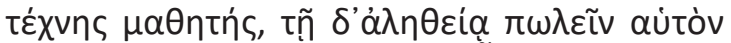

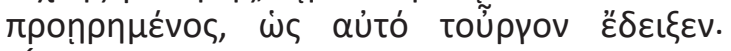
(ÉSQUINES, Contra Timarco, 1.40) 
Podemos verificar que a tradução de Dover é completamente inadequada. Ele verte

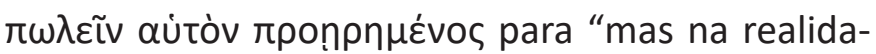
de para aprender os costumes homossexuais". Uma tradução bem mais acertada, e, portanto, muito mais autorizada, é a de Charles Darwin Adams na edição bilíngue da obra de Ésquines KATA TIMARXOU para The Loeb Classical Library:

First of all, as soon as he was past boyhood he settled down in the Peiraeus at the establishment of Euthydicus the physician, pretending to be a student of medicine, but in fact deliberately offering himself for sale, as the event proved (ÉSQUINES, Contra Timarco, 1:40).

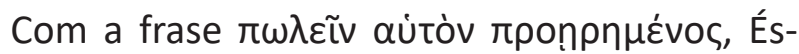
quines refere-se à prostituição de Timarco, offering himself for sale, como a tradução de Adams deixa bem claro, e não a costumes homossexuais, como quis Dover. Essa tradução errônea compromete toda a sua compreensão do fenômeno grego.

Ainda, Dover refere-se à erótica da Atenas clássica com termos como atos homossexuais e faz a seguinte pergunta: "Havia outras leis que penalizavam a homossexualidade não comercial?" (DOVER, 1994, p. 41, grifos nossos). Logo em seguida, ele afirma que, em Atenas, "evidências para um grau incomum de entusiasmo por relações homossexuais ou heterossexuais eram motivos para censuras morais." (DOVER, 1994, p. 41, grifos nossos). Também, pergunta-se "como era, efetivamente, o funcionamento da homossexualidade? Como ela era integrada à heterossexualidade, e como a avaliação moral e estética de comportamentos homossexuais, bons e maus, se relacionava com os valores da sociedade grega clássica de um modo geral?" (DOVER, 1994, p. 14, grifos nossos) e "até que ponto chegava a inibição dos atenienses ao falar de comportamentos homossexuais, e qual era o motivo para isso?" (DOVER, 1994, p. 41, grifos nossos)

É cabível questionar se, com o uso dos termos heterossexual e homossexual, a obra de Dover situa-se numa análise essencialista do homoerotismo ateniense. É no que acreditamos. Nos termos de Halperin, Dover não usa as categorias "homossexual" e "heterossexual" de forma descri- tiva. Essas categorias, em $A$ homossexualidade na Grécia Antiga, não denotam simplesmente relações sexuais entre pessoas do mesmo sexo ou entre pessoas de sexo oposto. Elas são usadas de forma substantiva ou normativa, posto que psicologias e comportamentos sexuais modernos estão implicados na análise. Dessa forma, a compreensão do fenômeno grego fica bastante prejudicada, já que, por essa via, Dover, sem o perceber, transfere para a Atenas clássica toda a caracterização psicológica e comportamental do par heterossexualidade/homossexualidade, todo o repúdio moderno aos homossexuais e todo o desequilíbrio maniqueísta produzido pelo embate entre essas duas identidades modernas. Há, na obra de Dover, uma grande dificuldade de se diferenciar paiderastía de homossexualidade. No fundo, a paiderastía não é analisada em suas especificidades, em sua historicidade, já que Dover projeta para o mundo grego as experiências das categorias modernas da sexualidade. Percebemos quase uma continuidade entre a "homossexualidade" e a "heterossexualidade" gregas e os fenômenos modernos.

Depois de traduzir um trecho do parágrafo 41 do Contra Timarco, em que Ésquines fala de Misgolas, "um homem distinto em todos os aspectos, e de nenhuma forma criticável, mas possuído por entusiasmo extraordinário por esta atividade" (DOVER, 1994, p. 45), Dover complementa: “i.e., relações homossexuais" (DOVER, 1994, p. 45, grifos nossos). Nesse trecho, Ésquines alude ao entusiasmo extraordinário de Misgolas por prostitutos como Timarco. O que Ésquines critica e condena é a prostituição e não a 'homossexualidade', a qual - usando os termos de koselleck - não sendo uma conceituação do mundo grego, não pertencia ao tempo histórico daquele universo cultural. Mais uma vez, Dover usa de forma indevida o termo homossexual. Confundido as categorias eróticas gregas e modernas, ou melhor, igualando-as, Dover incorre num erro conceitual (História dos Conceitos) que incide numa imprecisão e incompreensão no que se refere aos tempos históricos. Ousamos considerar essencialista esta obra de Dover por que o autor faz um uso indevido dos conceitos de hetero- e homossexualidade, ao estendê-los substantiva ou normativamente à cultura grega. 
Há, portanto, um grande problema teórico nessa obra de Dover que prejudica a sua análise da erótica grega. Ele não pode falar, de forma alguma, de sentimentos e comportamentos homossexuais entre os gregos. Quando dois homens, na Grécia Antiga, estabelecem um ato erótico, eles não estão movidos por um sentimento homossexual nem desempenham comportamentos homossexuais. Atribuir àquele ato erótico sentimento e comportamento homossexuais é interpretar mal a cultura grega. É tentar traduzir o erótico no mundo grego com categorias de outra matriz cultural. É não perceber as especificidades da cultura, das identidades e das práticas gregas. É não compreender a temporalidade histórica. É atribuir à condição/identidade da homossexualidade um caráter de naturalidade. Um ato erótico entre dois homens no mundo grego só pode ser entendido se for analisado a partir das referências culturais do próprio mundo grego condensadas nesse mesmo ato.

Um grego da Antiguidade não possui uma identidade homossexual. Nem heterossexual. Portanto, os gregos não possuem sentimentos e comportamentos heterossexuais ou homossexuais. Suas identidades eróticas são outras, forjadas com elementos de sua própria cultura. Tanto lá como aqui, pode-se dizer que o desejo é o mesmo, pois é natural: um homem sente desejo pelo corpo jovem de um rapaz. Nisso há naturalidade. Podemos dizer que este desejo é natural. Mas o significado cultural que se dá a esse desejo, os modos de percebê-lo, valorizá-lo, senti-lo, modelá-lo, circunscrevê-lo e praticá-lo, o que delimita uma identidade forjada por elementos culturais diversos incrustados num determinado tempo histórico, são muito distintos de uma cultura (Grécia Antiga) para outra (Modernidade). Dover toma desejo (natural) por identidade (cultural).

O desejo erótico de um homem por outro homem ou de um homem por uma mulher está presente, evidentemente, no mundo grego, mas não as identidades homossexual e heterossexual. O desejo entre pessoas do mesmo sexo (fato natural), por si só, não é condição suficiente para caracterizar a homossexualidade (fato cultural). O mesmo se dá com a heterossexualidade. Para o desejo entre pessoas do mesmo sexo no mundo grego, Dover usa o termo homossexualidade, esquecendo-se de que esta categoria implica numa identidade moderna inexistente na cultura grega. A cultura grega operava identidades eróticas em outro registro, o que Dover não levou em consideração ou não percebeu. No fundo, essa obra de Dover mais confunde que esclarece a respeito das identidades da erótica grega na Antiguidade.

"Como, quando e por que a homossexualidade aberta e sem repressão se tornou um aspecto tão conspícuo da vida grega é um assunto interessante para especulações" (DOVER, 1994, p. 14, grifos nossos), questiona-se Dover. Como se os gregos, a partir de um dado momento, passassem a "tolerar" ou "aceitar" a "homossexualidade". Para ele, é intrigante, embora presumivelmente benéfico aos seus olhos do final da década de 1970, o fato de que os gregos "não reprimiam" a "homossexualidade". Por isso, ele se pergunta como os gregos integraram a "homossexualidade" à "heterossexualidade". Entretanto, o mundo grego antigo não conheceu nem a "heterossexualidade", nem a "homossexualidade" ou sua "repressão".

Dover descreveu os caracteres exteriores dessa erótica, mas não soube dar significados a eles a não ser a partir das categorias modernas, o que obscurece completamente o entendimento da erótica e da cultura gregas. Enfim, Dover não enxergou o essencial: a explicação do comportamento erótico dos gregos não passa pelas categorias modernas. Em outra passagem da obra, Dover afirma:

\begin{abstract}
A antiga tradição europeia ocidental, de que o eros homossexual é essencialmente diabólico, pode ser responsável por uma certa relutância, mesmo por parte daqueles que imediatamente rejeitaram uma condenação da homossexualidade per si, em reconhecer que o eros homossexual pode inspirar tanta devoção altruísta quanto o heterossexual (DOVER, 1994, p. 78).
\end{abstract}

Tal forma de colocar a questão pressupõe a aceitação de que as identidades homossexual e heterossexual são naturais e universais. Neste tipo de abordagem, basta haver desejos eróticos entre homens ou entre homem e mulher para que se verifique automaticamente a homossexualidade e a 
heterossexualidade, o que já se tornou uma análise histórica completamente anacrônica e impertinente para a abordagem construcionista do campo erótico.

Parece que a obra $A$ homossexualidade na Grécia Antiga, no fundo, surpreendente e contraditoriamente, possui um tom homofóbico velado, não obstante o seu caráter pioneiro e não desmerecendo a sua importância para os estudos do homoerotismo grego. Dover seria, inconscientemente, um homofóbico? No prefácio da obra, o autor adverte:

O uso estabelecido da linguagem me obriga a tratar 'homossexual' e 'heterossexual' como antíteses, mas se eu fosse seguir minhas inclinações, substituiria 'heterossexual' por 'sexual', tratando da assim chamada 'homossexualidade' como uma subdivisão do 'quasesexual' (ou 'pseudo-sexual'; mas não 'parassexual'). (DOVER, 1994, p. 8. Grifos nossos)

O autor lança em seguida um desafio: "Qualquer um que pretender me impressionar, atribuindo esta minha inclinação a preconceitos, precisará, primeiro, convencer-me que tentou, seriamente, fazer uma distinção entre preconceito e julgamento". A provocação não impressiona e não se sustenta. $O$ repto é um vazio jogo de palavras que não convence e não carece de refutação. Não merece refutação. A sua posição é muito clara: para ele, a heterossexualidade é, em algum nível, superior à homossexualidade, tanto em 1978 quanto na Grécia Antiga.

William A. Percy é enciclopedista, historiador e professor da Universidade de Massachusetts. Tornou-se um ativista gay, juntando-se, em 1982, à luta por direitos iguais para os gays e começou a publicar nos Gay Studies três anos mais tarde. Autor de algumas obras sobre o fenômeno homoerótico grego e sobre a História da Homossexualidade ${ }^{6}$, ele vai bem mais longe em sua acusação da homofobia de Dover. Num minúsculo comentário a respeito da obra A homossexualidade na Grécia Antiga, Percy

\footnotetext{
${ }^{6}$ Entre elas, encontram-se: Encyclopedia of Homosexuality; Outing: Shattering the Conspiracy of Silence; Pederasty and Pedagogy in Archaic Greece; The Age of Recovery: The Fifteenth Century.
}

considera que Dover difamou a paiderastía quando este clama que ela era meramente lasciva, pervertida. A crítica procede, posto que a "homossexualidade degradante" de Timarco dá o tom da obra de Dover.

Teoricamente, Percy acusa Dover de ter sido erroneamente guiado por seu colaborador, o psicanalista George Devereux ${ }^{7}$, que o teria instruído com a distorcida tese freudiana de que os homossexuais são retardados, isto é, os homossexuais seriam imaturos por não terem conseguido passar de forma madura das fases oral e anal para a fálica. ${ }^{8}$

Metodologicamente, Percy critica Dover por se recusar a usar fontes posteriores ao século IV a.C., como as Vidas de Plutarco, ou os trabalhos de Luciano e Diodoro, que citaram e parafrasearam muitas fontes clássicas perdidas, as quais, elas próprias, muitas vezes, baseavam-se em relatos orais e escritos antigos. O efeito deste procedimento teria sido a simplificação da tarefa da obra e a distorção de suas conclusões. Desafia a razão, afirma Percy, como uma seleção de fontes de envergadura tão curta poderia esperar engendrar uma tese válida! ${ }^{9}$

Para Dover, em sua concepção essencialista da categorização erótica, a homossexualidade e a heterossexualidade são universais, naturais e ahistóricas. Além do mais, conforme Percy, ainda que

\footnotetext{
${ }^{7}$ Originalmente, a obra Greek Homosexuality seria escrita com a colaboração de George Devereux. DOVER, 1994, p. 9. Dover baseia-se em várias obras de George Devereux: Tragédie et poésie grecque: études ethnopsychanalitiques; Ethnopsychanalyse complémentariste; The nature of Sappho's seizure in $\mathrm{fr}$ 31 LP as Evidence of her Inversion e a medonha Greek Pseudo-homosexuality and the 'Greek Miracle'.
}

${ }^{8} \mathrm{O}$ comentário de William A. Percy encontra-se disponível em: http://www.amazon.com/gp/cdp/member-reviews/AUZT24FOU439H/ ref $=c m \_p d p \_r e v \_a l l$ ?ie Acesso em: 15/10/2008. Segundo OHAYON, Stephen. The psychopathology of Self-mutilation in the life of the contemporary patient. In: GOLDBERG, Jane G. Psycho-therapeutic treatment of cancer patients. Washigton, D.C.: Library of Congress, 1990, p. 80, "Freud considerava a homossexualidade uma defesa contra o temor da situação incestuosa e George Devereux considerava a homossexualidade o produto da repressão edipiana."

9 Disponível em: <http://www.williamapercy.com/pub-Comments-Dover.htm>. Acesso em: 20/04/2008. 
Dover tente afirmar o contrário, essa polaridade erótica é expressa de forma hierarquizada em sua obra: a homossexualidade possui um status naturalmente inferior em relação à heterossexualidade.

Sir Kenneth James Dover nasceu em 1920, em Londres. Fora educado em St. Paul's School antes de ir estudar no Balliol College, Oxford. Serviu à Artilharia Real Britânica durante a Segunda Guerra Mundial e foi mentioned in despatches ${ }^{10}$ por seus serviços na Itália. Após o serviço militar, retornou a Oxford e tornou-se membro e tutor em seu antigo College em 1948. Em 1955, foi nomeado Professor de grego para a University of St. Andrews, e tornou-se duas vezes Dean ${ }^{11}$ da Faculty of Arts da Universidade durante o período de vinte e um anos em que permaneceu nessa instituição. Em 1975, foi eleito para a Royal Society of Edinburgh. Em 1976, tornou-se presidente do Corpus Christi College, Oxford, posto que ele manteve por dez anos. Em 1977, foi condecorado com o título de Sir (knighthood) por serviços prestados à erudição grega. Em 1978, foi eleito para a presidência da British Academy, da qual ele era membro desde 1966, cargo que serviu por um período de três anos. Em 1981, retornou a St. Andrews como reitor honorário - Chancellor da Universidade. Fora o primeiro Chancellor na história da Universidade que não era nem nobre nem arcebispo. Durante os anos 1980, também marcou posições na Cornell University e na Stanford University.

Dover publicou A homossexualidade na Grécia Antiga aos cinquenta e oito anos de idade. Em 1969, ano simbólico e desencadeador da "revolução" homossexual, ele já era um homem maduro, na altura

\footnotetext{
${ }^{10}$ Mentioned in Despatches (MID) é um prêmio militar prodigalizado pela valentia ou outro serviço louvável. Um despatch é um relatório oficial de um comandante sênior, usualmente de um exército, enviado a seus superiores, detalhando a conduta de operações militares.

${ }^{11}$ Dean é um professor com significativa autoridade em uma unidade acadêmica específica ou em uma área de interesse específico, ou em ambas. Nas universidades do Reino Unido, o Dean é a cabeça de uma faculdade, um ajuntamento de departamentos acadêmicos relacionados, como, por exemplo, Dean of the Faculty of Arts and Humanities. Em universidades colegiadas como Oxford e Cambridge, cada college pode ter um Dean responsável por disciplina. O Dean pode também ser responsável pela organização e funcionamento da capela do college.
}

de seus 49 anos. Formou-se e viveu, da infância à primeira maturidade, na era pré-Stonewall, entre as décadas de 1920 e 1950. Além do mais, tratando-se de um inglês, mergulhado num ambiente cultural ainda bastante influenciado pela moralidade vitoriana incrustada em instituições centenárias, não é de se espantar que as inclinações de Dover, em 1978, sob o influxo de um hoje ultrapassado freudianismo ministrado pela autoridade psicanalítica de um George Devereux, levaram-no a tratar teoricamente da assim chamada homossexualidade como uma subdivisão do quase-sexual ou pseudo-sexual. Nesses termos, o completo-sexual, o verdadeiro-sexual era a heterossexualidade. Tal percepção da homossexualidade deve- se exatamente a sua primeira formação, ao primeiro mundo cultural no qual se formou, entre 1920 e 1950 . Seria muito surpreendente se ele tivesse uma percepção mais positiva em relação à homossexualidade, o que o lançaria a uma posição de avant garde no trato do assunto.

Qual a imagem temporal ${ }^{12}$ da homossexualidade e do fenômeno grego na obra de Dover? Se, por um lado, Dover está na esteira de um significativo, amplo e barulhento movimento "revolucionário", com suas ramificações nos campos estudantil, imaginário, comportamental, feminista e homossexual, fermentando-se entre as décadas de 1960 e 1970, por outro, podemos considerar que sua formação intelectual e seu modo de pensar e encarar a sexualidade devem estar estreitamente atrelados a sua primeira formação, moldada entre as décadas de

${ }^{12}$ Cf. KOSELLECK, 2006. REIS, 1994, p. 80, avaliando a especificidade do Tempo Histórico em R. Koselleck, diz que, para esse autor, "a questão maior posta pelo tempo histórico é: como, em cada presente, as dimensões temporais do passado e do futuro foram postas em relação? Sua resposta a esta questão é sua hipótese sobre o 'ser' do tempo histórico: determinando a diferença entre passado e futuro, entre 'campo da experiência' e 'horizonte de espera', em um presente, é possível apreender alguma coisa que seria chamada de 'tempo histórico'". Ver também REIS, 2000. Nessa obra, Reis aplica o conceito de Tempo Histórico de Koselleck no âmbito de uma Historiografia Brasileira, isto é, a tensão entre Espaço de Experiência e Horizonte de Expectativa em Varnhagen, Capistrano de Abreu, Gilberto Freyre, Sérgio Buarque de Holanda, Caio Prado Junior, Nelson Werneck Sodré, Florestan Fernandes, FHC, evocando, nesses autores, a Imagem Temporal do Brasil. Por meio deste mesmo arcabouço teórico de Koselleck, utilizado por Reis para a análise da Historiografia Brasileira, é possível descrever a Imagem Temporal (melhor, as imagens temporais) da homossexualidade e do fenômeno grego na sucessão dos autores e instituições da modernidade canônica. 
1920 e 1950. Sua herança, no que tange ao campo erótico, são dois mundos culturais até certo ponto antagônicos entre os quais ele está tentando se equilibrar e cujas forças refletem-se em sua obra, o que produziu o acriticismo e a incongruência de parte de seus resultados. Ele aponta a emergência, a quase onipresença e a voluptuosidade da paiderastía na imagética e na discursividade presentes no corpus documental grego, mas, lê-as com os olhos obsedados pelo conservadorismo vitoriano nas lentes distorcidas de um freudianismo equivocado. O tempo parece não ter mudado: a homossexualidade e a heterossexualidade parecem já estar lá na Grécia Antiga e adquirem capacidade explicativa universal. Homossexualidade e paiderastía se igualam, referindo-se, praticamente, ao mesmo fenômeno - o moderno. Dover, com isso, não pôde discutir o cerne da paiderastía grega. Visto que não pôde demarcar um campo conceitual, uma história dos conceitos, vislumbrou apenas os caracteres exteriores do fenômeno grego sem adentrar sua complexidade cultural e seu tempo histórico. Portanto, não há uma distinção da qualidade ou especificidade temporal no que tange à construção desses conceitos e à substância a que eles se referem. Além do mais, não vendo diferenças substanciais entre paiderastía e homossexualidade, ambas são moralmente inferiores em sua transistoricidade: o desejo entre iguais é quase-sexual ou pseudosexual, tanto na ordem burguesa quanto na Atenas Clássica.

Basicamente, o mesmo pode ser dito da obra Greek Erotica on Attic Red-Figure vases. Em 1993, Martin F. Kilmer a publica na mesma linha de $A$ homossexualidade na Grécia Antiga, e seguindo os padrões interpretativos e metodológicos de Dover ${ }^{13}$,

\footnotetext{
${ }^{13}$ No prefácio de sua obra, Kilmer congratula a obra de Dover: "Um obrigado particular é devido a Sir Kenneth Dover, que, além de prover um excelente exemplo em sua obra Greek Homosexuality, leu uma boa parte do livro em versões anteriores: eu devo muito aos seus comentários e sugestões, e ao seu encorajamento.", p. viii. Na introdução da obra, tomando emprestado de Dover os Números R (sistema de referência das imagens de vasos gregos baseado nas obras Attic Red-Figure Vase-Painters e Paralipomena de Sir John Beazley), Kilmer diz que usará esses números, "em parte porque eles permitem um meio simples de comparação, onde tal se aplica, entre este livro e Greek Homosexuality de Dover (o qual eu considero como um dos mais importantes trabalhos escritos nos últimos cem anos sobre a sexualidade grega antiga)", p. 5.
}

com uma análise similarmente descritiva e essencialista da erótica grega. Kilmer afirma no prefácio a respeito de seu próprio livro: "Sua principal proposta é organizar a evidência combinando ilustração e descrição. Interpretação (outra que não a interpretação da evidência visual, descrição do que está acontecendo) é, na maior parte do livro, um objetivo secundário." (KILMER, 1993, p. vii)

Nessa obra, Kilmer faz uma análise descritiva de um conjunto de imagens eróticas em uma série de vasos áticos de figuras vermelhas. O período de produção dessa série estende-se, aproximadamente, de 520 a 460 a.C. Bothmer argumenta que o escopo do livro não é realmente Greek Erotica on attic red-figure vases, mas Erotic subjects on attic vases between 520-460 B.C. ${ }^{14}$, isto é, o autor não trata em profundidade da erótica grega, mas descreve aspectos eróticos dos sujeitos/temas sem mínima referência à sociedade e à cultura de uma forma mais ampla. Na avaliação de Sutton Jr., "a maior parte do livro ocupa-se com o estabelecimento de uma tipologia impessoal dos vários atos e posições sexuais retratados" (SUTTON Jr., 1997, p. 413). Diante da interpretação superficial de Kilmer, o qual descarta, num só golpe, Foucault, Halperin e Winkler, Sutton Jr. vai mais longe em sua crítica à Greek Erotica, afirmando que:

Embora este livro seja útil por agrupar evidências dispersas, suas análises e conclusões deixam muito a desejar. Enquanto muitos pesquisadores estudam a prática sexual da Grécia Antiga como um aspecto da sociedade antiga, na maior parte, Kilmer estuda sexo simplesmente enquanto sexo e suas análises sociais são muitas vezes desenvolvidas ad hoc, sem amplo suporte. Sua discussão faz extensivo uso da pesquisa sexual de Masters e Johnson, ao passo que negligencia até a erudição básica sobre relevantes instituições sociais antigas tais como a de Herter sobre a prostituição e a de Himmelmann sobre a representação da

\footnotetext{
${ }^{14}$ BOTHMER, 1995, p. 82. Nesse artigo, Bothmer comenta uma série de erros interpretativos cometidos por Kilmer em suas análises da iconografia dos vasos em pintura vermelha. A conclusão geral do artigo é a de que Kilmer erra muito em suas análises iconológicas devido a sua escassa familiaridade com todos os aspectos técnicos da pintura em vasos gregos, bem como seu pouco conhecimento da cultura grega.
} 
escravidão. Num trabalho que toma parte tanto da história social quanto da iconografia, Kilmer exibe pouca compreensão da sociedade antiga, da análise social ou da teoria representacional. Para explicar as pinturas de vasos, ele geralmente oferece explicações fisiológicas e mecânicas ou, alternativamente, procura causas artísticas estéticas ou práticas em vez de discutir seriamente suas dimensões sociais ou psicológicas no contexto da sociedade grega antiga (SUTTON Jr., 1997, p. 413).

Kilmer não apresenta uma estrutura teórica social, a não ser uma visão empírica positivista implícita e passiva que a evidência fala por si própria. Seu interesse é pelo sexo per se, e não pela sociedade. Sua fonte fundamental sobre sexualidade, além de Dover, parece ter sido a obra, de Masters e Johnson, sobre a fisiologia da sexualidade humana. Ele chega aos resultados de sua obra com uma bagagem de arqueologia clássica em um momento anterior à voga da teoria social explícita. Sua obra fora essencialmente escrita antes que Halperin e Winkler escrevessem a maior parte das suas e para a sua abordagem um tanto quanto mecânica e biológica sobre o sexo, as obras de Foucault não tinham o menor sentido. Sua bagagem intelectual e seus interesses acadêmicos não o fizeram ir além de Dover, cuja obra, no momento em que fora escrita, pareceu bastante avant garde, pelo menos em termos acadêmicos. Enfim, Kilmer tenta ser receptivo a novas ideias, mas não é bem sucedido e não possui real entendimento da teoria social da sociedade.

Similarmente a Dover, Kilmer fala de orientação homo e heterossexual na Atenas Clássica. Ou seja, outra vez, essas categorias são usadas de forma substantiva ou normativa, posto que psicologias e comportamentos sexuais modernos estão implicados também na análise deste autor. $\mathrm{Na}$ introdução da obra, o autor diz: "No capítulo 6, sobre acessórios sexuais, o material está dividido de acordo com os acessórios e/ou a ocasião, e dentro dessa categoria, de acordo com a orientação (homossexual, heterossexual)." (KILMER, 1993, p. 6, grifos nossos). Outra vez, a homossexualidade e a heterossexualidade já então presentes lá na Grécia Antiga. Que longa duração! Nessa forma de olhar a realidade histórica, a longa duração de tais categorias torna-se óbvia, e torna-se eterna duração enquanto houver ser humano, pois são, para estes autores, essências humanas.

Kilmer sugere também que a "homossexualidade" ateniense é imatura. Sobre as pinturas de um vaso do pintor Peithinos, ele comenta: “...e o vaso de Peithinos, com cortes homossexuais de um lado e heterossexuais do outro, mostra a que todos esses relacionamentos adolescentes supõem levar: relacionamentos heterossexuais maduros." (KILMER, 1994, p. 14-15, grifos nossos). Podemos concluir com essa afirmação que Kilmer considera imaturo o contato erótico entre dois homens na relação erastés/erómenos, a qual ele chama de homossexual. Seguindo a sua lógica, o homossexual (grego ou moderno) é imaturo.

Dover, em 1978, e Kilmer, em 1993, fazem uma análise empírica, descritiva e essencialista da paiderastía grega, o que os impediu de fazer uma análise cultural/antropológica em profundidade que os possibilitasse explicar o seu objeto, restituí-lo ao seu tempo histórico e demarcar as diferenças temporais entre Classicismo e Modernidade. Suas teorias e seus métodos impossibilitaram-nos de analisar este objeto em sua própria temporalidade. Dover, secundado por Kilmer, seguindo uma tradição interpretativa oxfordiana de estudos arqueológicos, estava completamente alheio à contínua revolução na escrita da história que ocorria de diversas maneiras do outro lado do Canal da Mancha. No mesmo ano de 1978, em Paris, sob a direção de Jacques Le Goff, é publicada a obra La Nouvelle Histoire. Quatro anos antes, em 1974, também em Paris, sob a direção de Jacques Le Goff e Pierre Nora, fora publicada a trilogia Faire de L'histoire. Em 1975, Michel de Certeau publicara L'écriture de l'histoire. Em 1976, Michel Foucault já havia publicado La volonté de savoir, o primeiro título da trilogia Histoire de la Sexualité. E em 1979, Reinhart Koselleck publicara sua importantíssima obra Vergangene Zukunft. Zur Semantik geschichtlicher Zeiten. O potencial interpretativo e o método de $A$ homossexualidade na Grécia Antiga eram diametralmente opostos aos que já vinham sendo praticados pelos historiadores franceses. Le Goff, por exemplo, advertia, em La Nouvelle Histoire, que o historiador devia "evitar uma definição demasiado ampla, que coloque sob um mesmo rótulo realidades demasiado distantes 
no tempo e no espaço e que não dependam de sistemas históricos comparáveis" (LE GOFF, 2001, p. 55). Parafraseando Le Goff, poderíamos dizer que a Paiderastía grega, no fundo, não tem muita coisa a ver com a homossexualidade moderna, esta própria a ser diferenciada em várias fases. Dover e Kilmer, também, não se interessaram pelas novas abordagens de outra "revolução historiográfica" estabelecida na década de 1960, aquela empreendida na própria Inglaterra pela New Left Review, representada por autores como Christopher Hill, Edward Thompson, Perry Anderson, Eric Hobsbawn.

Em 1984, Jaques Mazel publicou sua obra As metamorfoses de Eros: o amor na Grécia Antiga. $\mathrm{O}$ autor incorre no mesmo erro de usar de forma substantiva ou normativa as categorias hetero- e homossexualidade ao analisar as metamorfoses do eros grego. A certa altura do capítulo "Alcibíades ou o amor convivial", tecendo comentários sobre o Banquete de Xenofonte, Mazel diz:

Seduzidos por seu encanto soberano, Cálias e seus amigos são subjugados pela personalidade do jovem Autólicos. Como todos esses gregos não amariam esse jovem adolescente de quinze anos, que por sua vitória deu provas de "força de caráter, resistência, coragem e temperança", sem contudo deixar de ser "radiante de pudor e de continência?" (MAZEL, 1984, p. 68)

Nada há de surpreendente, para o mundo grego, nessa pergunta que o autor lança. No entanto, comparando-a com outro comentário do autor feito anteriormente, ficamos sem entender qual critério Mazel usa para qualificar alguém como 'homossexual' no mundo grego. Ele diz:

Com Xenofonte, deixemos por um instante Alcibíades, mas sem deixar sua família, já que somos convidados a partilhar a festa de Cálias, seu cunhado homossexual, cuja herança foi logo cobiçada e que dificilmente poderia esperar um herdeiro (MAZEL, 1984, p. 67. Grifo Nosso)

Ambiguidade à parte, constatamos mais uma vez a confusão, ou antes, a não distinção, entre categorias eróticas gregas e modernas. Se, para Mazel, Cálias pode ser considerado um 'homossexual', como ele classificaria todos os outros gregos que ele diz que amariam Autólicos? Em outras palavras, uma expressão como "seu cunhado homossexual" soa muito moderno! Por que enfatizar a 'homossexualidade' do cunhado? Todos os outros gregos, supracitados por Mazel, também seriam, na ótica do autor, 'homossexuais'?

No mesmo banquete, continua Mazel, Cármides fica maravilhado com um dançarino citaredo e exclama: "Meus amigos, parece-me que, como disse Sócrates a propósito do vinho, a beleza desse menino, associada aos seus cantos, suaviza os desgostos e faz nascer o amor" (MAZEL, 1984, p. 68). E Sócrates interroga o 'cenarista': "Então não dormes com ele? - Sim, todas as noites, e a noite inteira! Por Hera, tens uma sorte extraordinária! A natureza te dotou de uma pele única, que não corrompe os que dormem contigo. Podes orgulhar-te dessa pele, à falta de outra coisa." (MAZEL, 1984, p. 68) Ora, pela lógica de Mazel, todos eles são, pode-se concluir, 'homossexuais'? Reinam na análise empreendida em As metamorfoses de Eros a ambiguidade e a falta de uma distinção das categorias eróticas.

\section{DOVER, KILMER, MAZEL: ESSENCIALIST HISTORIOGRAPHY OF GREEK HOMOEROTICISM}

\begin{abstract}
This article analyzes the essentialist mode in which the historians Kenneth Dover, Martin Kilmer and Jacques Mazel approached Greek homoeroticism in a time after the Stonewall event (1969).
\end{abstract}

Keywords: Greek Homoeroticism, Historiography, Dover, Kilmer, Mazel.

\section{REFERÊNCIAS BIBLIOGRÁFICAS}

AESCHINES. Against Timarchus. Cambridge \& London: Harvard University Press \& William Heinemann Ltd., 1988. 
BOTHMER, Dietrich von. [untitled] Reviewed work: Greek Erotica on Attic Red-Figure Vases by Martin F. Kilmer. The Classical Journal, Vol. 91. № 1, (Oct. - Nov., 1995), p. 82-86.

BUFFIÈRE, Félix. Eros adolescent: la pédérastie dans la Grèce antique. Paris: Les Belles Lettres, 1980.

CAMBIANO, Giuseppe. Tornar-se homem. In: VERNANT, Jean-Pierre (org.). O homem grego. Lisboa: Editorial Presença, 1994.

CANTARELLA, Eva. Bisexuality in the ancient world. London/New Haven: Yale University Press, 1992.

DEMAND, Nancy. [untitled] Reviewed work: Greek Homosexuality by K. J. Dover. The American Journal of Philology, Vol. 101, no 1, 1980, p. 121-124.

DOVER, Kenneth J. A homossexualidade na Grécia Antiga. São Paulo: Nova Alexandria, 1994.

ELIAS, Norbert. O processo civilizador 1: Uma história dos costumes. Rio de Janeiro: Jorge Zahar, 1994.

O processo civilizador 2: Formação do estado e civilização. Rio de Janeiro: Jorge Zahar, 1993.

FOUCAULT, Michel. História da sexualidade: a vontade de saber. 13a edição, Rio de Janeiro: Graal, 1988.

História da sexualidade: a vontade de saber. Rio de Janeiro: Graal, 1977a.

História da sexualidade: o uso dos prazeres. Rio de Janeiro: Graal, 1984.

História da sexualidade: o cuidado de si. Rio de Janeiro: Graal, 1985.

GOLDBERG, Jane G. Psycho-therapeutic treatment of cancer patients. Washington: Library of Congress, 1990.

HALPERIN, David M. One hundred years of homosexuality and other essays on Greek love. New York, London: Routledge, 1990.

KILMER, Martin F. Greek erotica on attic red-figure vases. London: Duckworth, 1993.

KOSELLECK, Reinhart. Futuro passado: contribuição à análise dos tempos históricos. Rio de Janeiro: Contraponto: Ed. Puc-Rio, 2006.

LE GOFF, Jacques. A História Nova. São Paulo: Martins Fontes, 2001.

LE GOFF, Jacques. A política será ainda a ossatura da História? In: O maravilhoso e o Quotidiano no Ocidente Medieval. Lisboa: Ed. 70, 1990.

MAZEL, Jacques. As metamorfoses de eros: o amor na Grécia antiga. São Paulo: Martins Fontes, 1988.
OHAYON, Stephen. The psychopathology of Self-mutilation in the life of the contemporary patient. In: GOLDBERG, Jane G. Psycho-therapeutic treatment of cancer patients. Washigton: Library of Congress, 1990.

PERCY, William Armstrong. Encyclopedia of Homosexuality. 2 volumes, New York: Garland Publishing, 1990.

PERCY, William Armstrong. Pederasty and pedagogy in Archaic Greece. Chicago: University of Illinois Press, 1996.

PERCY, William Armstrong; JOHANSSON, Warren. Outing: Shattering the conspiracy of silence. New York: Haworth Press, 1994.

PERCY, William Armstrong; JOHNSON, Jerah. The Age of Recovery: The Fifteenth Century. New York: Cornell University Press, 1970.

PLATO. Symposium. Vol. III. Cambridge \& London: Harvard University Press, 1991.

REIS, José Carlos. As identidades do Brasil: de Varnhagen a FHC. 3a edição, Rio de Janeiro: Editora FGV, 2000.

REIS, José Carlos. Tempo, História e Evasão. Campinas: Papirus, 1994.

ROBINSON, T. M. [untitled] Reviewed work: Greek Homosexuality by K. J. Dover. Phoenix, Vol. 35, no 2, (Summer, 1981), p. 160-163.

SALLES, Catherine. Nos submundos da antiguidade. 3a edição, São Paulo: Brasiliense, 1987.

SARTRE, Maurice. Ritos e prazeres gregos. Caderno Mais, Folha de São Paulo, p. 6-7, 31 de outubro de 1999.

SCARBOROUGH, John. [untitled] Reviewed work: Greek Homosexuality by K. J. Dover. The American Historical Review, Vol. 84, no 4, (Oct., 1979), p. 1028-1029.

SPENCER, Colin. Homossexualidade: uma história. 2a ed., Rio de Janeiro: Record, 1999.

SUTTON Jr., Robert F. [untitled] Reviewed works: Before Sexuality: The construction of Erotic Experience in the Ancient Greek World by David M. Halperin; John J. Winkler; Froma I. Zeitlin; One Hundred Years of Homosexuality and Other Essays on Greek Love by David M. Halperin; The Constraints of Desire: The Anthropology of Sex and Gender in Ancient Greece by John J. Winkler. The Classical Journal, Vol. 87, no 2, (Dec., 1991 - Jan., 1992), p. 189-191.

SUTTON Jr., Robert F. [untitled] Reviewed work: Greek Erotica on Attic Red-Figure Vases by Martin F. Kilmer. American Journal of Archaeology, Vol. 101, no 2, (Apr., 1997), p. 413-414.

XENOPHON. Memorabilia. Vol. IV. Cambridge \& London: Harvard University Press \& William Heinemann Ltd., 1979. 